\title{
Mobile Society, Technology, and Culture
}

\author{
Mieczysław Muraszkiewicz \\ The Institute of Theoretical and Applied Informatics, Polish Academy of Sciences, Gliwice, \\ Poland \\ mietek@mimuw.edu.pl
}

\begin{abstract}
The paper takes into account three vital categories, namely mobile society, technology, and culture. Our world gets mobile. More and more people carry out their activities on the move; it might be business, entertainment, education or just socializing. Communications become wireless and invisible, and cheaper and cheaper, the distance and location factors get increasingly irrelevant. We are quickly approaching the point beyond which we shall have good reasons to think in terms of mobile society. The purpose of this paper is to investigate certain relationships between new technologies, especially the Internet and mobile technologies, and culture. It seems that technology and culture work in opposite directions. Even a more dramatic diagnosis seems to be legitimate, viz. technology displaces culture. The major message of this discourse is that: One has to vividly oppose to the displacement of culture. The rationale is simple, viz. a decline and atrophy of culture is in many ways an extremely negative phenomenon for democratic society at large, which at the end of the day will also affect the technology itself. Towards this end, the MOST Programme (Mobile Open Society through wireless Telecommunications) was started; a short note on its objective is given in the paper.
\end{abstract}

Key words: technology, information and communications technology, culture, education, moral autonomy

\section{INTRODUCTION}

The paper takes into account three vital categories, namely mobile society, technology, and culture. The so called developed countries are

The original version of this chapter was revised: The copyright line was incorrect. This has been corrected. The Erratum to this chapter is available at DOI: 10.1007/978-0-387-35616-7_23 
quickly approaching the point beyond which we shall have good reasons to think of the people living there in terms of mobile society. This type of society is a result of deep transformations mainly caused by a triumphal march of information and communications technology (ICT) and an incredible development of transportation systems, in particular airlines over last sixty years. The ICT and technology as a whole have dramatically influenced almost all the facets of our life, including economy, where we are witnessing the process of establishing a new global economic order. They have also had a tremendous impact on culture and our personal living standards and habits. There are very little doubts that technology has positively shaped economy; however, one may have a number of reservation as far as the influence of technology on culture is concerned.

It seems that technology and culture work in opposite directions. Even a more dramatic diagnosis seems to be legitimate, viz. technology displaces culture. The emptied room is immediately sized by the technology itself and a mass/popular culture, including its political and ideological incarnations such as nationalism and totalitarism, or on the other extreme - political indifferentism. The major message of this discourse is that: One has to vividly oppose to the displacement of culture. We have to do it for the sake of culture, technology itself and all of us.

The itinerary of our discourse is planned as follows. We shall start with the notion of mobile society, then we shall take a look at information and communications technology, and its influence on the economic order, showing its character and the way it influences individuals and communities. We shall also characterize certain generic features of technology as such. Next, using the same pattern, we shall take into account culture, and investigate a relationship between technology and culture. The discussion will be completed by a note on the MOST Programme that has been conceived as one of the means to harmonize mobile technology and an open society building process.

Before entering upon any further details a terminological reservation is needed. For the sake of this paper we isolate, which is a bit risky decision, the term technology from the semantic field of the notion of culture. It is a temporary act aimed at facilitating the examination of the relationship linking up both terms. Having completed our analysis both terms should return to their nests. In addition, a note of warning is necessary: during the discourse controversial points will sometimes be issued; hopefully, within a tolerance margin of the reader. 


\section{MOBILE SOCIETY}

Our world gets mobile. More and more people carry out their activities on the move. It might be business, learning, entertaining, or just socializing. Communications has become wireless and invisible, and cheaper and cheaper. The distance and location factors are increasingly irrelevant. Today, we witness the end of the first phase of the new civilization process that could be summarized as a procurement of a ubiquitous communications facility to connect people. A club of countries where the cellular phones penetration level exceeded $30 \%$ is no more a narrow niche on the global map. With a prospective wide availability of the broadband UMTS platform, connectivity and bandwidth will cease to be the limiting factors. Accessing, sending and receiving data, speaking and watching via mobile handsets will be soon a prose of the daily life.

Further on, the term mobile will be used to characterize:

- individuals and groups of individuals on the move;

- portable electronic end-user devices allowing one for information processing and/or communications, e.g. mobile phones, laptops, palmtops, etc.;

- technological facilities for providing connectivity and information transmission between portable (mobile) end-user devices, e.g. a cellular telephony country-wide network,

- services that are available by means of mobile technology facilities and devices, e.g. payments done via a handset.

It is observed that people tend to consider applications and content as utilities (water, electricity, etc.), and they do not want them standing alone. They want one place to go to access them. And for those on the move a handset is this place. Every day we can see how the online world is becoming a global digital marketplace and social communications agora, full of shopping malls, commercial content, chat forums, learning platforms, subject oriented empowerment facilities, communities of practices, etc. For that reason the role played by content creators such as artists, journalists and researchers as well as the involvement of content providers like publishers and editors will get stronger and stronger. It's only a matter of time when the contribution of the content community to the digital business, culture, education and other areas will reach a critical mass in terms of quantity and quality, and as a result, will in one way or another take over the control of the digital world development.

Mobile technology, based on wireless solutions, offers us a possibility to be "always on", to hear and to be heard regardless of the place where we are. On the other hand, it seems that beyond such an obvious practical reason there exist in our human nature more fundamental needs, which are the 
desire of being actual part of the community that we belong to, and a very deep need of freedom. Owing to the "always on" factor the mobile phones ensure a permanent linkage with the members of the community - one can be on the move, one's friends or collaborators might be on the move as well, yet, contacts have not been broken, and thereby our basic need for participation and affiliation is fulfilled. Thanks to this we do not feel alone, or at least we are less alone. Regarding the feeling of freedom we should remember that there are two types of freedom, namely freedom from and freedom to. Undoubtedly, a handset enhances our freedom to as it offers us a possibility to communicate with people on business or on private matters anytime and anywhere. This linkage provides us with a comfortable feeling that if we only want we can always be in and do not lose the connection with our professional and social environments. Commenting on the freedom from in terms of cellular phones, let us recall a bright saying by a great Polish poet Julian Tuwim, who defined radio as follows: It is a clever invention, you can switch it off just by pressing a button. Needless to say that handsets also include similar functionality. Now, getting back to a serious tone we may emphasize the fact that wireless telecommunications is highly instrumental in terms of maintaining social relationships and enhancing individual freedom. In addition, it should be noted that its ubiquity and a deep impact on our life cause that it cannot be considered simply as a commercial enterprise. It is not either a typical commodity that can be bought and sold like any other merchandise; it is also to a large extent a public service and responsibility. It is, therefore, important that people have the rights to make use of communications facilities and to get information, wherever and whenever they wish so.

\section{INFORMATION AND COMMUNICATIONS TECHNOLOGY}

Let us take a closer look at the information and communications technology (ICT), which owing to its significance for the economic and societal transformation deserves more attention. The major components of ICT are: computer hardware, software, telecommunications means and what is considered equally important - the interrelationship of these components. There is no doubt that that they are subject to deep, rapid and long lasting revolution. Miniaturization of the equipment, its growing performance and reliability accompanied by a dramatic decrease of prices, and a tremendous progress in terms of tools for rapid development of userfriendly software applications, and an explosion of wireless telecommunications, in particular mobile phones have no comparable 
precedent in history. The essence of the novelty consist in a combination of three elements, i.e. computer, telecommunications and information. This specific set-up, ménage à trois, features an amazing dynamism and at the same time stability (aren't triangles the most stable arrangements in our life ?). The convergence of media is part of this process. We see how quickly radio, TV, fax, telephone, Internet and press have become available on one integrated digital platform. We see how a new unified information universe is being created, which is a dense space where living habits and conditions are getting more and more different from what we know from the past. It is worth mentioning that in addition to traditional social and economic divides the so-called digital divide is emerging. Schematically, this means that there are two types of communities, namely those who use the new media and communications facilities and those who do not. This divide, alas, corresponds to the division between rich, powerful and influential people and communities, and those who are poor and deprived of hope and chance. Unfortunately, this division has also a less visible aspect, i.e. the advantages and pitfalls are not equally divided between the rich and the poor (mobile phones are a good illustration of this note). A lion's share of good things goes to the richer, whereas the bad and hazardous things go to the unprivileged.

As a complement to the above remarks we should explain what is the basis of the media convergence and integration. Towards this end, the major factor is a digital recording or digitalization of information. Whatever the information medium, be it paper, a film tape, a magnetic tape, photographic paper, etc., one is able to convert the information residing on these media into a digital form (as sequences of bits), which can easily be stored, mixed, merged, and processed by a computer, and then transmitted by radio or cable any time, to any place and for any user in the world. Noteworthy, the impact of the media convergence on content and its perception is a stimulating and exciting topic, still hardly investigated. It is interesting to note, that the media convergence takes place not only on a technical platform. One observes a continual consolidation of large media corporations. TV channels purchase publishing houses, set up joint ventures with internet providers and software houses, and so on and so forth (e.g. AOL bought Time Warner, Microsoft acquired NBC).

\section{ICT AND NEW ECONOMIC ORDER}

Putting aside the controversy surrounding the overused term new economy, there is no doubt that deep, quite often unstructured and unrecognized, social and economic processes are taking place throughout 
various facets of our life these days. Their features are, inter alia, globalization, deregulation, distribution, high competitiveness, mobility, risk taking, speed, change, lifelong learning, orientation towards information and knowledge with a crucial role of intellectual property, and extensive use of the ICT. It is an approach where information and knowledge, and the mechanisms of networking and sharing knowledge are at the core of all activities. It seems that the world that is now being created is paradigmatically different from the world that is going away. The difference can be formulated as follows: Owing to Information and Communications Technology, in particular the Internet and mobile technology, while reaching one's objectives, costs of cooperation are becoming lower than costs of competing.

There exist already a number of indications and convincing examples sustaining this assertion. One may be sure that this new economic and social trend is not a temporary result of a peculiar inclination of human beings to novelties and technology itself, but it is a durable result of a precise calculation and cool reasoning, which is the best guarantee that this trend and its products will succeed and survive in the future. Noteworthy, one can identify a positive feedback effect between the new economic and social phenomena and the ICT, i.e. the ICT drives new trends and vice versa new facts boost the ICT and technology as a whole.

\section{TECHNOLOGY}

Pragmatically speaking, technology refers to the universe of tools and machines that the man uses for transforming both material and immaterial world, or in other words, it is a means to make human's life effortless, painless, trouble-free and more interesting, and more than often to strengthen military capacities. It includes also expertise, hidden mainly in procedures instructing us how to use the tools. Noteworthy, technology deals not only with manufacturing and production, it is also concerned with services, and last but not least, it facilitates social communications.

With a little risk we can predict that an average interlocutor's reaction to the word technology will be positive. Technology, along with modern science, which is legitimately considered to be its mother, is perceived as a major factor of economic and societal transformations we are witnessing these days. Technology is regarded as a mighty and somewhat mysterious force that can help resolve human problems. This generally positive attitude is commonplace though people are usually aware of and remember well all dramatic threats and negative consequences the technology can cause. Examples of Hiroshima and Chernobyl, of thaliomid and BSE, acid rains, 
greenhouse effect - to mention just a few cases only, are still remembered traumas. In a sense, from today's perspective technology has become the Stendhalian mirror carried down the middle of a road and reflecting the major problems, dilemmas and tendencies of our time.

Why is our overall attitude vis-à-vis the technology in general positive ? Marshal MacLuhan explains that technology extends and strengthens human attributes and qualities, e.g. an excavator adds forces to our muscles, a microscope reinforces eyes, a bike makes locomotion easier and faster, and a computer increases our intellectual capabilities. The latter has done it in such a broad, deep and efficient way that these days we are in the transformation process from an industrial or postindustrial society to the so-called information society where conventional growth factors (capital, labor, natural resources, energy, etc.) become less critical giving way to information, knowledge and innovation. To MacLuhan's theory justifying the attractiveness of technology we add the following: Technology strengthens our individual and collective ego.

Shortly speaking, we perceive technology as a source of power, which by allowing us to govern or even rule the world provides us with a peculiar contentment and pleasure. Technology encourages us to conquer the world, to domination, to a constant transformation of the environment according to our will and ad-hoc needs, quite often based on sheer hedonism and selfishness. Of course, it is not to say that technology automatically encourages or imposes a totalitarian order and stratifies people so that those who have it mastered exploit or subordinate those who have no access to the technology or do not know how to use it. There is no fatalistic reason that this has to be the case; yet, it may happen and actually happens at a smaller or larger scale.

A final comment on technology is as follows. McLuhan has claimed that the media we use change people's cognitive structures arguing that the effects of technology do not occur at the level of opinions or concepts, but alter sense ratios or patterns of perception steadily and practically without resistance. Along the same line goes Neil Postman's reasoning "Technology is ideology and to maintain that technology is ideologically neutral is stupidity plain and simple." In this context one might ask: Well, we have been exposed to technology for ages and we have always been subject to control, so what's new with the ICT ? Surely not the drive for control. We have been seeing it since the beginning of the mankind. What is potentially new are: (i) the means of control, i.e. the computer itself and computer networks along with intelligent sensors and artificial agents; and (ii) the target of control: our thinking. The Orwellian Big Brother can enter the world of our thoughts and feelings. Fortunately, there exists a consolation, offered by Melvin Kranzberg's law: "Technology is neither good nor bad, 
nor is it neutral.". In fact, the ICT itself has quite often turned out instrumental in the process of civic society building, in strengthening and inspiring culture, and it is also an efficient tool for boosting education and medical care. The hope is that the ICT, including its mobile manifestation, will bring more benefits than downsides. To a large extent it depends on ourselves.

\section{CULTURE}

Culture is noticeably different from technology. In this paper we understand culture in its rather broader sense, though, in an arbitrary way, which is not necessarily consistent and compatible with what professionals and researchers have usually in mind. For us, it is an invisible universe of symbols, beliefs, sophisticated relations, values, laws, responsibilities, and duties that have been constructed and established over long history of the mankind. This amalgam is incredibly stable and remains almost unchanged in the course of time. Culture tends to avoid changes. By its very nature it is conservative. Culture is an abstract entity that is deeply rooted in a human's psyche. We admit that its various materializations, or the so called material culture (obviously, technology is part of material culture), taking the forms of artistic activities, art products, educational systems, etc. are visible items, indeed; yet, the culture itself like a shadow is deeply hidden somewhere in Plato's cave. If a vivid dynamo was a relevant metaphor for technology, obviously, the right metaphor for culture is a homeostatic device whose principal objective is to maintain the status quo. Culture is a controlling mechanism which imposes values and behavioral patterns. Culture's charisma is soft, it does not provoke immediate results; however, its efficiency is admirable. Culture transforms individuals and non-coherent groups into communities and societies. Having realized the features of culture and using again the Freudian language we may say: Culture tempers and moderates our individual and collective ego.

Generally, yet with a little precision, one may say that culture discourages from expansion and exploration, and rewards conservatism and conformism. Shortly speaking: in principle, culture harnesses ego. This is not to say that culture promotes laziness and keeps people in lethargy, that there is no movement and progress within its kingdom; it is rather to say that culture strictly determines, or better to say - constrains the fields of activities, contenting itself with the known, and avoiding the unknown. 


\section{TECHNOLOGY AND CULTURE}

Our so far discussion leads us to the point where we can summarize the situation as follows. Technology and culture work in the opposite directions, i.e. technology strengthens ego, whereas culture moderates it. Already at the first glance one can see that technology wins the confrontation with culture, mainly because the technology is at a short term stronger than the culture. While looking around one can readily identify facts sustaining this observation, which is especially visible in the context of a pop/mass culture that in fact is a tribute to smart applications of technology in the fields of entertainment, marketing, leisure, lifestyle, etc. Having written the above we dare to formulate the following rule: Technology tends to displace culture.

In other words, culture steps down under the pressure of technology. The emptied room is immediately sized by the technology itself or a mass/popular culture, which comes more or less to the same thing. As a result, culture gradually abandons a general public and is forced onto procrustean bed of elitarian audience. Neil Postman has noticed "Culture always pays a price for technology", and adds "the greater the technology, the greater the price." We can append: the greater the technology, the greater risk to damage culture, and the greater the harm. Indeed, the mass culture is usually a vicious mixture of stereotypes and socio-manipulations. The fascination for technology, gadgets, a quest for constant change for the sake of change only, the elaboration of new irrational applications whose only motivation is a profit regardless of sense and negative educational impact are the phenomena that can be hardly supported and justified, especially that they hit directly or indirectly the "cultural tissue" of the society. Even worse is a naive attitude of devoted technocrats who believe that the most serious problems we have in the world are the result of inadequate technology and insufficient information. All this sounds dramatic, indeed, especially that we should remember that culture defines our identity and the sense of life, it provides us with a social anchor, and last but not least, culture is the major protection facility that defends us from external and internal evil, contempt, barbarism, hate, etc. Unfortunately, this protection has not always turned out reliable enough; yet, one may ask: do we have a better armor at our disposal?

Unluckily, it seems that rapid technological changes and surprising inventions not only put the culture in a state of disarray but also increase the level of incertitude as far as individuals and communities are concerned. People lose the sense of continuity, perceive the surrounding world as an unstable stage attacked by unidentified temptations and threats. Perhaps, the following allegation holds: The level of incertitude and existential anxiety are proportional to the scale of technological achievements. 
Let us supplement the above with two additional observation, viz:: (i) the more admired is a technology at the point of its introduction, the more disappointing it is when it fails and its originally invisible pitfalls and threats emerge at surface and become widely known; (ii) the more powerful and effective is a technology, the lower becomes the level of human's attention and eagerness, e.g. it has been noticed on many occasions that the availability of effective medications may decrease diagnostic abilities of medical doctors.

It is time to recapitulate our so far reasoning. The winning technologies flatter, add force and fortify our ego, but at the same time they raise its incertitude that expresses itself in the form of misunderstood anxiety. Unfortunately, religion is not a panacea for getting rid of this incertitude since the incertitude of this kind has no spiritual origins and dimension; it is just the inquietude and the problem of our ego, which is far away from divine matters. We know that culture is a panacea, but as we have just demonstrated, the trouble is that the culture is being displaced by technology. Under these circumstance, as nature abhors vacuum, the pop/mass culture starts playing the role of a tranquilizer and stopper of the incertitude with all the consequences of this fact, one of which is paradoxically the increase of anxiety (a classic vicious circle effect).

The major message of this paper is that: We have to oppose to the displacement of culture.

The rationale is simple: a decline and atrophy of culture is in many ways an extremely negative phenomenon which at the end of the day will affect not only ourselves, but it will also destruct the technology itself. Technology is a materialization and manifestation of our desires which, as we perfectly know it, are fed by an insatiable hunger of our imagination and instincts. This is why the self-control and self-limiting regulators of technology are so weak, and thereby the technology is inherently weak, too. The conclusion is straightforward: one has to help technology to free itself from its in-born thoughtless and aggressive inclinations.

\section{THE MOST PROGRAMME}

In order to promote and support the concept that ICT and its mobile incarnation can boost democratic society building without hampering culture, Warsaw University of Technology, together with Polska Telefonia Cyfrowa, and the German mobile operator, T-Mobil, started a Programme under the name of MOST (Mobile and Open Society Through Wireless Telecommunications) during the CeBIT'2001 Exhibition in Hanover. The concept of the MOST is prompted by the pressing need for generating 
interdisciplinary thinking and acting synergy between research scholars, practicing industry executives, content providers, and decision makers who share a strong interest in the topics of information society, mobile economy, and higher education models based on interactions within and between humans and information systems. The objectives of MOST include the construction of an efficient mechanism for the flow of thought and knowhow, exchange of experiences and personnel between universities and suppliers of telecommunication services, as well as the widely understood media (publishers, magazines, television, radio, etc.). It also seeks to find solutions to concrete problems through joint projects of a technical character, projects of a business character (e.g., new business models in the field of the m-commerce), and undertakings of a educational character (e.g. distance education), or sociological research. These goals can be further categorized as follows:

- To establish a facility for providing systematic transfer of cutting-edge technical knowledge, creative ideas and people within a triangle: University - Industry - Content Providers.

- To set up a channel for flowing experience, skills and stimulating research problems to be resolved from Industry and Content Providers to University.

- To set up a regional community of mobile practices.

- To provide awareness on civic wireless society.

The MOST community works on setting up a sound and workable regional mechanism that will organize broad cooperation between universities, research centers and laboratories, wireless telecommunications providers and content providers operating in Central Europe and Eastern Europe. MOST as is firmly stressed by its founders, is an initiative open for all those interested in its topic and goals. More details about the MOST Programme are available at: www.most-program.org. 